\title{
max \\ MDCT Findings in Gastrointestinal Perforations and the Predictive Value according to the Site of Perforation
}

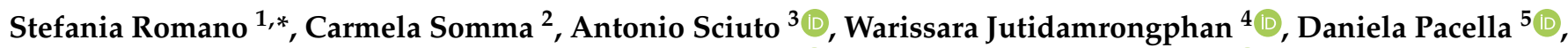 \\ Francesco Esposito ${ }^{3}$, Marta Puglia ${ }^{1}$, Claudio Mauriello ${ }^{3}{ }^{\circledR}$, Khanin Khanungwanitkul ${ }^{4}{ }^{\mathbb{D}}$ and Felice Pirozzi ${ }^{3}$
}

\section{check for}

updates

Citation: Romano, S.; Somma, C.;

Sciuto, A.; Jutidamrongphan, W.;

Pacella, D.; Esposito, F.; Puglia, M.;

Mauriello, C.; Khanungwanitkul, K.;

Pirozzi, F. MDCT Findings in

Gastrointestinal Perforations and the

Predictive Value according to the Site

of Perforation. Tomography 2022, 8,

667-687. https://doi.org/10.3390/

tomography 8020056

Academic Editor: Iacopo Carbone

Received: 25 October 2021

Accepted: 24 January 2022

Published: 3 March 2022

Publisher's Note: MDPI stays neutral with regard to jurisdictional claims in published maps and institutional affiliations.

Copyright: (C) 2022 by the authors. Licensee MDPI, Basel, Switzerland. This article is an open access article distributed under the terms and conditions of the Creative Commons Attribution (CC BY) license (https:// creativecommons.org/licenses/by/ $4.0 /)$.

1 Department of Radiology, “S. Maria delle Grazie” Hospital, 80078 Pozzuoli, Italy; marta.puglia@aslnapoli2nord.it

2 Department of Neuroradiology, “Umberto I” Hospital, 80131 Nocera, Italy; csomma89@gmail.com

3 Department of Surgery, "S. Maria delle Grazie" Hospital, 80078 Pozzuoli, Italy; antonio.sciuto@aslnapoli2nord.it (A.S.); francesco.esposito1@aslnapoli2nord.it (F.E.); claudio.mauriello@aslnapoli2nord.it (C.M.); felice.pirozzi@aslnapoli2nord.it (F.P.)

4 Department of Radiology, Faculty of Medicine, Prince of Songkla University, Hat Yai, Songkhla 90110, Thailand; warissara.jut@gmail.com (W.J.); khanin14@gmail.com (K.K.)

5 Department of Public Health, Federico II University of Naples, 80131 Naples, Italy; daniela.pacella@unina.it

* Correspondence: stefromano@libero.it

\begin{abstract}
Background: Gastrointestinal perforations are a frequent cause of acute abdominal symptomatology for patients in the emergency department. The aim of this study was to investigate the findings of multidetector-row computed tomography of gastrointestinal perforations and analyze the impact of any imaging signs on the presurgical identification of the perforation site. Methods: We retrospectively reviewed emergency MDCT findings of 93 patients submitted to surgery for gastrointestinal perforation at two different institutions. Two radiologists separately reviewed the emergency MDCT examinations performed on each patient, before and after knowing the surgical diagnosis of the perforation site. A list of findings was considered. Positive predictive values were estimated for each finding with respect to each perforation site, and correspondence analysis (CA) was used to investigate the relationship between the findings and each of the perforation types. Results: We did not find inframesocolic free air in sigmoid colorectal perforations, and in rare cases, only supramesocolic free fluid in gastroduodenal perforations was found. A high PPV of perivisceral fat stranding due to colonic perforation and general distension of upstream loops and collapse of downstream loops were evident in most patients. Conclusions: Our data could offer additional information on the perforation site in the case of doubtful findings to support surgeons, especially in planning a laparoscopic approach.
\end{abstract}

Keywords: MDCT; intestinal perforations; pneumoperitoneum; acute abdomen; surgery; emergency

\section{Introduction}

Gastrointestinal (GI) perforations are common surgical emergencies, accounting for approximately $3 \%$ of acute abdomen syndrome cases [1]. They consist of discontinuities of the GI wall that allow the intestinal lumen and the extraluminal space to communicate. Breaches can appear due to different causes, such as peptic ulcers, inflammatory bowel disease, blunt or penetrating trauma, iatrogenic factors, foreign bodies or neoplasms [2-5]. Early diagnosis of a GI tract perforation, together with identification of the site and cause, can facilitate treatment and improve prognosis, having a great impact on therapeutic management, including the type of surgery or a focused conservative choice [6]. Clinical diagnosis of the exact site of GI tract perforation may be difficult, as the clinical signs and symptoms may be nonspecific. Consequently, the role of the emergency radiologist appears crucial, as the final diagnosis is mainly based on imaging results, particularly on CT [7]. Patients with acute abdominal pain and clinical suspicion of bowel perforation are usually 
first submitted to $X$-ray examination, and the direct radiographic sign of bowel perforation is represented by the evidence of free abdominal gas. However, to answer the surgical question regarding the site of perforation, $\mathrm{CT}$ examination is the most accurate tool to allow a diagnosis [8]. The predictive value of MDCT to detect the site of perforation has been already investigated by several authors and the results of studies already published in the radiologic literature: distribution of free air, concentration of extraluminal air bubbles, segmental bowel wall thickening, focal defect of the bowel wall, etc. $[9,10]$. More recently, predictors of perforation at different GI tract sites have been reported: focal bowel wall discontinuity for the stomach, duodenal bulb and left colon; mottled extraluminal air bubbles for the retroperitoneal duodenum and right colon; and segmental bowel wall thickening for the small bowel [11]. However, in radiological clinical practice in the emergency department, sometimes, correlating imaging findings with a suggestive site of perforation may not be easy, and data from the literature are not always applicable.

The aim of this study was to investigate the MDCT findings of patients who underwent emergency surgery for gastrointestinal perforations and re-evaluate them according to the site of lesion in order to analyze the impact of imaging signs on the presurgical identification of the perforation site.

\section{Materials and Methods}

A retrospective evaluation of the surgical database of adult patients who presented at the emergency department between January 2017 and August 2019 at two different institutions (Santa Maria delle Grazie Hospital in Pozzuoli, Italy, and Songklanagarind Hospital in Songkhla, Thailand) with acute abdominal symptomatology and submitted to surgery for gastrointestinal tract perforation was performed. As this was a retrospective study with anonymization of all personal patient data included in the review process, no local Ethical Committee permission was required in our institutions. We retrospectively reviewed the emergency MDCT imaging findings of 93 adult patients: 58 from Santa Maria delle Grazie Hospital and 35 from Songklanagarind Hospital (59 men (63.4\%) and 34 women $(36.5 \%)$ with a mean age of 66.7 years old)), with final diagnosis of gastrointestinal perforation and submitted to surgery within $12 \mathrm{~h}$. CT scans of the abdomen were performed using one of the following scanners available at the two institutions: Dual Source DECT 128 detector row scanner (Somatom Drive, Siemens Healhineers), two 64 MDCT scanners (Lightspeed GE; Ingenuity, Philips) at Santa Maria delle Grazie Hospital, 160 detector rows MDCT (Aquilion Prime, Toshiba) and DECT 512 detector rows scanners (Revolution, GE) at Songklanagarind Hospital.

Due to the different locations of the two institutions involved, as well as the retrospective nature of the study, the imaging methodology was heterogeneous; however, all patients underwent a CT scan in the supine position starting from the diaphragm down to the pubic symphysis (slice thickness of $2.5 / 3 \mathrm{~mm}$, back reconstructions at less than $1 \mathrm{~mm})$. Intravenous contrast medium was administered in all cases and oral contrast material in one patient. A precontrast abdominal scan was performed in all examinations on the single energy machines, whereas patients imaged with DE equipment underwent postcontrast scanning only. A contrast-enhanced phase CT was performed in most cases with a $55 \mathrm{~s}$ delay $(90-100 \mathrm{~mL}$ of iomeprol, infusion rate at $3 \mathrm{~mL} / \mathrm{s})$, followed by $30 \mathrm{~mL}$ of saline flush at the same injection rate. The images were retrospectively reviewed on dedicated workstations.

Two radiologists with different degrees of experience in abdominal and emergency radiology (one with 19 years' experience, one final-year resident at Santa Maria delle Grazie Hospital, one with 4 years' experience and one final-year resident at Songklanagarind Hospital) separately re-evaluated the axial and multiplanar reconstructions of the anonymized CT examinations using lung and soft tissue level window visualization. Both reviewers were blinded to any patient medical records but were informed that all cases had a surgical diagnosis of GI perforation. 
In the analysis of each CT scan, the following CT findings were evaluated before knowing the surgical diagnosis of the perforation site: intra- and retroperitoneal free air and its location; presence and distribution of air bubbles; free fluid; fluid collections; focal defect in the bowel wall, if visible; air/fluid intestinal loop distension; presence of collapsed loops; evidence of segmental or diffuse abnormal bowel wall thickening and enhancement.

After consulting the surgical diagnosis, a consensual re-evaluation of all CT exams and findings was performed, also considering the surgical point of perforation, in order to attest the features of GI segments located, respectively, upstream and downstream to the perforation site (with attention to the lumen, wall thickness and enhancement); appearance of the GI segment involved in perforation (with attention to the lumen, wall thickness and enhancement); presence of perivisceral fat stranding; and presence of perivisceral fluid collection.

All data were collected with Excel 15.34 (@ 2022 Microsoft Corporation, Washington, WA, USA).

Data are reported as frequency (percentages). The $p$-value on the contingency table was computed with the chi-square test. Positive predictive values were estimated for each finding with respect to each perforation type. False positives for each perforation site were considered as all the cases where the finding was present in the other sites of perforation. Correspondence analysis (CA) was used to investigate the relationship between the findings and each perforation type. Hierarchical clustering was performed on the CA dimensions to identify the clusters of associated findings. All analyses were performed using the statistical computing software $\mathrm{R}$ version 4.0.2.

\section{Results}

A review of the surgical database showed the following perforation sites: cecal appendix ( 3 cases), ascending colon ( 2 cases), cecum ( 2 cases), jejunum ( 5 cases), descending colon ( 5 cases), duodenum (13 cases), ileum (13 cases), rectum (4 cases), sigmoid colon ( 24 cases), stomach (18 cases) and transverse colon (4 cases).

We divided these sites of perforation into four groups to easily evaluate the predictive value of each CT sign: stomach and duodenum (Group A), small bowel loops (Group B), colon from the cecum to the descending colon (Group C) and sigmoid colon and rectum (group D).

All findings for each group are schematized in Tables 1 and 2.

Table 1. Contingency tables showing the frequencies of findings with respect to each perforation site. Data are presented as frequency and percentages (with $95 \%$ confidence interval). INTRA: intraperitoneal; SUPRA: supramesocolic; INFRA: inframesocolic; RETRO: retroperitoneal.

\begin{tabular}{|c|c|c|c|c|c|c|c|c|}
\hline & \multicolumn{2}{|c|}{$\begin{array}{c}\text { GROUP A } \\
(n=31)\end{array}$} & \multicolumn{2}{|c|}{$\begin{array}{l}\text { GROUP B } \\
(n=18)\end{array}$} & \multicolumn{2}{|c|}{$\begin{array}{c}\text { GROUP C } \\
(n=16)\end{array}$} & \multicolumn{2}{|c|}{$\begin{array}{l}\text { GROUP D } \\
(n=28)\end{array}$} \\
\hline & $n$ & $\%(95 \% \mathrm{CI})$ & $n$ & $\%(95 \% \mathrm{CI})$ & $n$ & $\%(95 \%$ CI $)$ & $n$ & $\%(95 \% \mathrm{CI})$ \\
\hline FREE AIR(FA) & 27 & $87(70-96)$ & 6 & $33(13-59)$ & 10 & $62(35-85)$ & 18 & $64(44-81)$ \\
\hline FA_INTRA & 25 & $81(63-93)$ & 4 & $22(6-48)$ & 10 & $62(35-85)$ & 15 & $54(34-72)$ \\
\hline FA_SUPRA & 16 & $52(33-70)$ & 2 & $11(1-35)$ & 3 & $19(4-46)$ & 7 & $25(11-45)$ \\
\hline FA_INFRA & 0 & $0(-)$ & 0 & $0(-)$ & 2 & $13(2-38)$ & 0 & $0(-)$ \\
\hline FA_SUPRA+INFRA & 9 & $29(14-48)$ & 2 & $11(1-35)$ & 5 & $31(11-59)$ & 8 & $29(13-49)$ \\
\hline FA_RETRO & 5 & $16(5-34)$ & 1 & $6(0-27)$ & 0 & $0(-)$ & 7 & $25(11-45)$ \\
\hline FA_INTRA+RETRO & 3 & $10(2-26)$ & 0 & $0(-)$ & 0 & $0(-)$ & 4 & $14(4-33)$ \\
\hline AIR BUBBLES(AB) & 27 & $87(70-96)$ & 11 & $61(36-83)$ & 10 & $62(35-85)$ & 23 & $82(63-94)$ \\
\hline AB_INTRA & 25 & $81(63-93)$ & 10 & $56(31-78)$ & 10 & $62(35-85)$ & 22 & $79(59-92)$ \\
\hline AB_SUPRA & 15 & $48(30-67)$ & 3 & $17(4-41)$ & 2 & $13(2-38)$ & 7 & $25(11-45)$ \\
\hline AB_INFRA & 0 & $0(-)$ & 6 & $33(13-59)$ & 2 & $13(2-38)$ & 4 & $14(4-33)$ \\
\hline AB_SUPRA+INFRA & 10 & $32(17-51)$ & 1 & $6(0-27)$ & 6 & $38(15-65)$ & 11 & $39(22-59)$ \\
\hline AB_RETRO & 3 & $10(2-26)$ & 1 & $6(0-27)$ & 3 & $19(4-46)$ & 9 & $14(41-79)$ \\
\hline AB_INTRA+RETRO & 1 & $3(0-17)$ & 0 & $0(-)$ & 4 & $25(7-52)$ & 7 & $25(11-45)$ \\
\hline FREE FLUID(FF) & 26 & $84(66-95)$ & 13 & $72(47-90)$ & 10 & $62(35-85)$ & 19 & $68(48-84)$ \\
\hline
\end{tabular}


Table 1. Cont.

\begin{tabular}{|c|c|c|c|c|c|c|c|c|}
\hline & \multicolumn{2}{|c|}{$\begin{array}{c}\text { GROUP A } \\
(n=31)\end{array}$} & \multicolumn{2}{|c|}{$\begin{array}{l}\text { GROUP B } \\
(n=18)\end{array}$} & \multicolumn{2}{|c|}{$\begin{array}{l}\text { GROUP C } \\
(n=16)\end{array}$} & \multicolumn{2}{|c|}{$\begin{array}{l}\text { GROUP D } \\
(n=28)\end{array}$} \\
\hline & $n$ & $\%(95 \% \mathrm{CI})$ & $n$ & $\%(95 \% \mathrm{CI})$ & $n$ & $\%(95 \% \mathrm{CI})$ & $n$ & $\%(95 \% \mathrm{CI})$ \\
\hline FF_INTRA & 26 & $84(66-95)$ & 13 & $72(47-90)$ & 8 & $50(25-75)$ & 17 & $61(41-79)$ \\
\hline FF_SUPRA & 2 & $6(0-21)$ & 0 & $0(-)$ & 2 & $13(2-38)$ & 0 & $0(-)$ \\
\hline FF_INFRA & 2 & $6(0-21)$ & 2 & $11(1-35)$ & 2 & $13(2-38)$ & 6 & $21(8-41)$ \\
\hline FF_SUPRA+INFRA & 22 & $71(52-86)$ & 11 & $61(36-83)$ & 4 & $25(7-52)$ & 11 & $39(22-59)$ \\
\hline FF_RETRO & 3 & $10(2-26)$ & 1 & $6(0-27)$ & 2 & $13(2-38)$ & 7 & $25(11-45)$ \\
\hline FF_INTRA+RETRO & 3 & $10(2-26)$ & 1 & $6(0-27)$ & 2 & $13(2-38)$ & 6 & $21(8-41)$ \\
\hline WĀLL THICKNESS & 26 & $84(66-95)$ & 11 & $61(36-83)$ & 11 & $69(41-89)$ & 21 & $75(55-89)$ \\
\hline WALL ENHANCEMENT & 26 & $84(66-95)$ & 14 & $78(52-94)$ & 4 & $25(7-52)$ & 12 & $43(24-63)$ \\
\hline \multirow[t]{2}{*}{ WALL DEFECT } & 13 & $42(25-61)$ & 8 & $44(22-69)$ & 4 & $25(7-52)$ & 9 & $32(16-52)$ \\
\hline & $n$ & $\%(95 \% \mathrm{CI})$ & $n$ & $\%(95 \% \mathrm{CI})$ & $n$ & $\%(95 \% \mathrm{CI})$ & $n$ & $\%(95 \% \mathrm{CI})$ \\
\hline FAT STRANDING & 18 & $58(39-75)$ & 9 & $50(26-74)$ & 14 & $88(62-98)$ & 24 & $86(67-96)$ \\
\hline NEXT TO PERF. LOOP & 18 & $58(39-75)$ & 9 & $50(26-74)$ & 14 & $88(62-98)$ & 11 & $39(22-59)$ \\
\hline NEXT TO UPSTREAM LOOP & 0 & $0(-)$ & 0 & $0(-)$ & 0 & $0(-)$ & 13 & $46(28-66)$ \\
\hline FLUID COLLECTIONS & 3 & $10(2-26)$ & 2 & $11(1-35)$ & 4 & $25(7-52)$ & 13 & $46(28-66)$ \\
\hline AIR BUBBLES CLOSE TO PERF. LOOP & 24 & $77(59-90)$ & 9 & $50(26-74)$ & 8 & $50(25-75)$ & 17 & $61(41-79)$ \\
\hline UPSTREAM LOOPS & $n$ & $\%(95 \% \mathrm{CI})$ & $n$ & $\%(95 \% \mathrm{CI})$ & $n$ & $\%(95 \% \mathrm{CI})$ & $n$ & $\%(95 \% \mathrm{CI})$ \\
\hline DISTENSION & 19 & $61(42-78)$ & 7 & $39(17-64)$ & 8 & $50(25-75)$ & 8 & $29(13-49)$ \\
\hline COLLAPSE & 4 & $13(4-30)$ & 5 & $28(10-53)$ & 2 & $13(2-38)$ & 13 & $46(28-66)$ \\
\hline NORMAL & 8 & $26(12-45)$ & 6 & $33(13-59)$ & 6 & $38(15-65)$ & 7 & $25(11-45)$ \\
\hline WALL THICKNESS & 12 & $39(22-58)$ & 5 & $28(10-53)$ & 4 & $25(7-52)$ & 15 & $54(34-72)$ \\
\hline ENHANCEMENT+ & 14 & $45(27-64)$ & 7 & $39(17-64)$ & 5 & $31(11-59)$ & 7 & $25(11-45)$ \\
\hline DOWNSTREAM LOOPS & $n$ & $\%(95 \%$ CI $)$ & $n$ & $\%(95 \% \mathrm{CI})$ & $n$ & $\%(95 \% \mathrm{CI})$ & $n$ & $\%(95 \% \mathrm{CI})$ \\
\hline DISTENSION & 6 & $19(7-37)$ & 3 & $17(4-41)$ & 3 & $19(4-46)$ & 7 & $25(11-45)$ \\
\hline COLLAPSE & 18 & $58(39-75)$ & 9 & $50(26-74)$ & 8 & $50(25-75)$ & 11 & $39(22-59)$ \\
\hline NORMAL & 7 & $23(10-41)$ & 6 & $33(13-59)$ & 5 & $31(11-59)$ & 10 & $36(19-56)$ \\
\hline WALL THICKNESS & 12 & $39(22-58)$ & 7 & $39(17-64)$ & 2 & $13(2-38)$ & 11 & $39(22-59)$ \\
\hline ENHANCEMENT+ & 13 & $42(25-61)$ & 7 & $39(17-64)$ & 3 & $19(4-46)$ & 7 & $25(11-45)$ \\
\hline
\end{tabular}

Table 2. Positive predictive values (PPVs) of each finding by perforation site.

\begin{tabular}{|c|c|c|c|c|}
\hline & $\begin{array}{l}\text { GROUP A } \\
\text { PPV (\%) }\end{array}$ & $\begin{array}{c}\text { GROUP B } \\
\text { PPV (\%) }\end{array}$ & $\begin{array}{c}\text { GROUP C } \\
\text { PPV (\%) }\end{array}$ & $\begin{array}{c}\text { GROUP D } \\
\text { PPV (\%) }\end{array}$ \\
\hline FREE AIR(FA) & 44 & 10 & 16 & 30 \\
\hline FA_INTRA & 46 & 7 & 19 & 28 \\
\hline FA_SUPRA & 57 & 7 & 11 & 25 \\
\hline FA_INFRA & 0 & 0 & 100 & 0 \\
\hline FA_SUPRA+INFRA & 38 & 8 & 21 & 33 \\
\hline FA_RETRO & 38 & 8 & 0 & 54 \\
\hline FA_INTRA+RETRO & 43 & 0 & 0 & 57 \\
\hline AIR BUBBLES(AB) & 38 & 15 & 14 & 32 \\
\hline AB_INTRA & 37 & 15 & 15 & 33 \\
\hline AB_SUPRA & 56 & 11 & 7 & 26 \\
\hline AB_INFRA & 0 & 50 & 17 & 33 \\
\hline AB_SUPRA+INFRA & 36 & 4 & 21 & 39 \\
\hline AB_RETRO & 19 & 6 & 19 & 56 \\
\hline AB_INTRA+RETRO & 8 & 0 & 33 & 58 \\
\hline FREE FLUID(FF) & 38 & 19 & 15 & 28 \\
\hline FF_INTRA & 41 & 20 & 13 & 27 \\
\hline FF_SUPRA & 50 & 0 & 50 & 0 \\
\hline FF_INFRA & 17 & 17 & 17 & 50 \\
\hline FF_SUPRA+INFRA & 46 & 23 & 8 & 23 \\
\hline FF_RETRO & 23 & 8 & 15 & 54 \\
\hline FF_INTRA+RETRO & 25 & 8 & 17 & 50 \\
\hline
\end{tabular}


Table 2. Cont.

\begin{tabular}{|c|c|c|c|c|}
\hline & $\begin{array}{l}\text { GROUP A } \\
\text { PPV (\%) }\end{array}$ & $\begin{array}{c}\text { GROUP B } \\
\text { PPV (\%) }\end{array}$ & $\begin{array}{c}\text { GROUP C } \\
\text { PPV (\%) }\end{array}$ & $\begin{array}{l}\text { GROUP D } \\
\text { PPV (\%) }\end{array}$ \\
\hline WALL THICKNESS & 38 & 16 & 16 & 30 \\
\hline WALL ENHANCEMENT & 46 & 25 & 7 & 21 \\
\hline \multirow[t]{3}{*}{ WALL DEFECT } & 38 & 24 & 12 & 26 \\
\hline & GROUP A & GROUP B & GROUP C & GROUP D \\
\hline & PPV (\%) & PPV (\%) & PPV (\%) & PPV (\%) \\
\hline FAT STRANDING & 28 & 14 & 22 & 37 \\
\hline NEXT TO PERF. LOOP & 35 & 17 & 27 & 21 \\
\hline NEXT TO UPSTREAM LOOP & 0 & 0 & 0 & 100 \\
\hline \multirow{2}{*}{$\begin{array}{c}\text { FLUID COLLECTIONS } \\
\text { AIR BUBBLES CLOSE TO } \\
\text { PERF. LOOP }\end{array}$} & 14 & 9 & 18 & 59 \\
\hline & 41 & 16 & 14 & 29 \\
\hline \multirow{2}{*}{ UPSTREAM LOOPS } & GROUP A & GROUP B & GROUP C & GROUP D \\
\hline & PPV (\%) & PPV (\%) & PPV (\%) & PPV (\%) \\
\hline DISTENSION & 45 & 17 & 19 & 19 \\
\hline COLLAPSE & 17 & 21 & 8 & 54 \\
\hline NORMAL & 30 & 22 & 22 & 26 \\
\hline WALL THICKNESS & 33 & 14 & 11 & 42 \\
\hline ENHANCEMENT+ & 42 & 21 & 15 & 21 \\
\hline \multirow{2}{*}{ DOWNSTREAM LOOPS } & GROUP A & GROUP B & GROUP C & GROUP D \\
\hline & PPV (\%) & PPV (\%) & PPV (\%) & PPV (\%) \\
\hline DISTENSION & 32 & 16 & 16 & 37 \\
\hline COLLAPSE & 39 & 20 & 17 & 24 \\
\hline NORMAL & 25 & 21 & 18 & 36 \\
\hline WALL THICKNESS & 38 & 22 & 6 & 34 \\
\hline ENHANCEMENT+ & 43 & 23 & 10 & 23 \\
\hline
\end{tabular}

The plot in Figure 1 also displays the findings in a concise view. The chi-square statistics on the contingency table show a significant association between the findings and the perforation site $(p<0.001)$. To better investigate the association, correspondence analysis was performed, and the results on the dataset, which has no missing values, are shown below. Figure 1 shows the scree plot of the CA. The first two dimensions express $76.93 \%$ of the total dataset inertia. The first factor is major: it expresses $52.49 \%$ of the data variability. An estimation of the right number of axes to interpret suggests restricting the analysis to the description of the first axis. This axis presents an amount of inertia greater than those obtained by the 0.95 quantile of random distributions (52.49\% against $52.12 \%$ ).

The biplot in Figure 2 shows the spatial relationship across the CA dimensions among findings and perforation sites.

Dimension 1 shows factors such as FAT STRANDING, FS NEXT TO PERF. LOOP, UL_DISTENSION, FF_SUPRA+INFRA and WALL ENHANCEMENT (to the right of the graph, characterized by a strongly positive coordinate on the axis) opposed to factors such as NEXT TO UPSTREAM LOOP, FLUID COLLECTIONS, FF_RETRO, AB_RETRO, FA_RETRO, AB_INTRA+RETRO and FA_INTRA+RETRO (to the left of the graph, characterized by a strongly negative coordinate on the axis).

The findings AB_RETRO, FF_RETRO, FF_INTRA+RETRO, FS NEXT TO UPSTREAM LOOP, FLUID COLLECTIONS, UL_ENHANCEMENT are highly correlated with the dimension (respective correlation of 0.96, 0.99, 0.97, 0.92, 0.97, 0.94 and 0.96), and Dimension 1 can be considered as being mainly explained by them.

A hierarchical cluster $(\mathrm{HC})$ analysis was also performed on the coordinates of the findings and perforation sites extracted from the $\mathrm{CA}$. The $\mathrm{HC}$ revealed four clusters, as in Figure 3. 


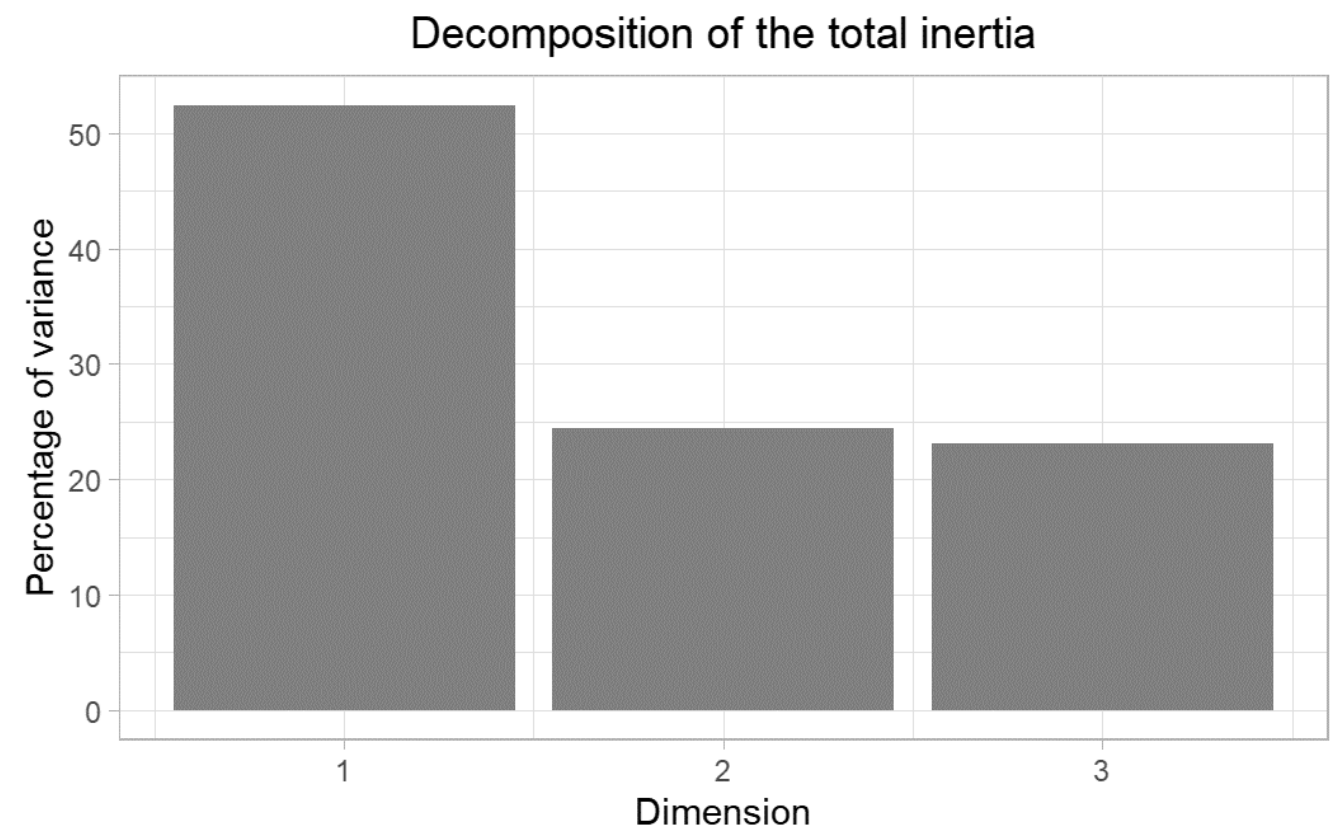

Figure 1. Scree plot showing the dimensions extracted from the CA and their explained variance.

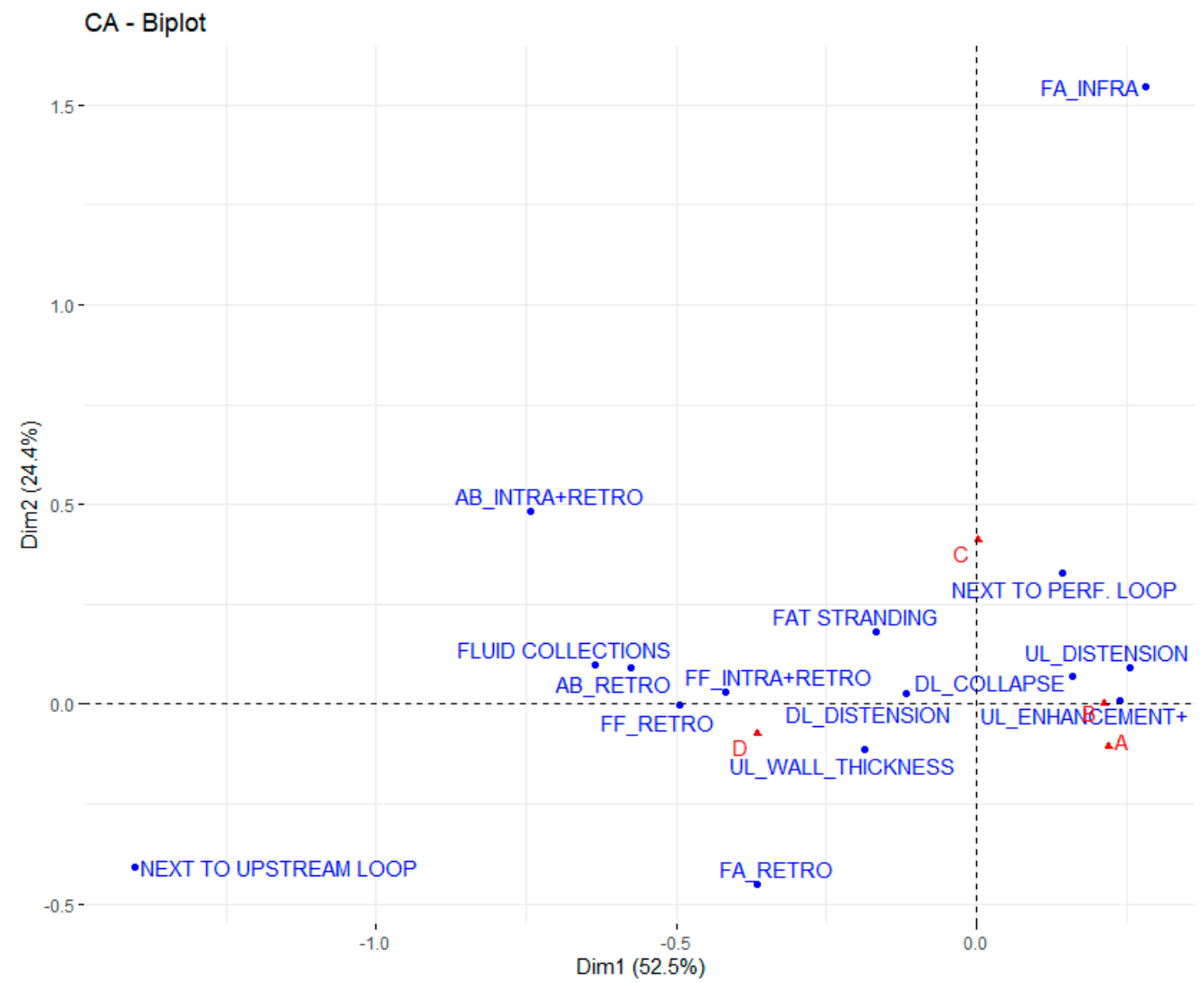

Figure 2. Biplot of spatial relationships across dimensions for each perforation site and finding. 


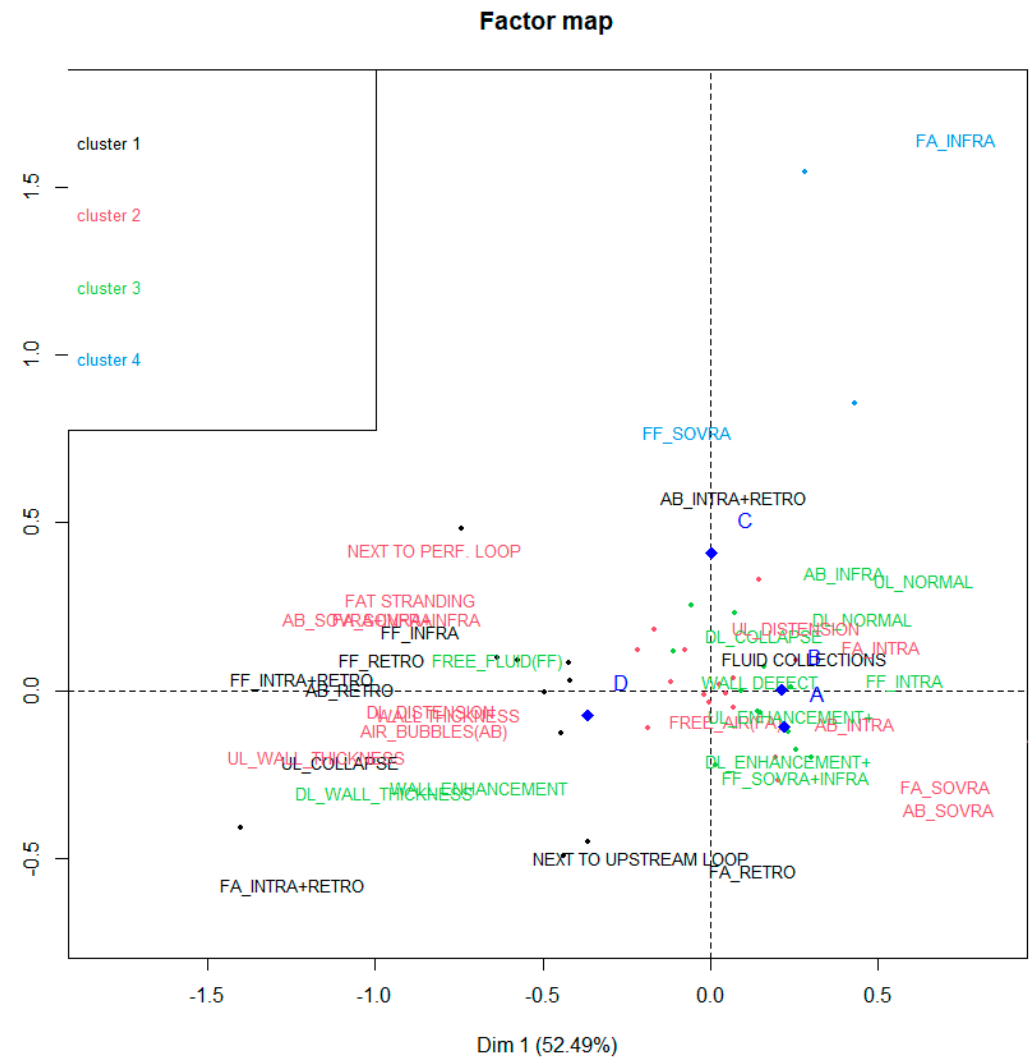

Figure 3. Cluster analysis performed on the results.

Cluster 1 is mainly identified by findings FS NEXT TO UPSTREAM LOOP, AB_INTRA+RETRO, FLUID COLLECTIONS, AB_RETRO, FF_RETRO, UL_COLLAPSE, FA_INTRA+RETRO and FA_RETRO. The cluster is characterized by significant:

- High occurrence of perforation site D;

- $\quad$ Low occurrence of perforation sites A and B.

Cluster 2, instead, is mainly identified by findings FAT STRANDING, FS NEXT TO PERF. LOOP, FA_SUPRA, AB_SUPRA and UL_DISTENSION. It is characterized by significant:

- High occurrence of perforation site A;

- $\quad$ Low occurrence of perforation site B.

Cluster 3 is identified by findings DL_WALL_THICKNESS, UL_NORMAL, FF_SUPRA+INFRA and WALL ENHANCEMENT and characterized by significant:

- $\quad$ High occurrence of perforation site A;

- $\quad$ Low occurrence of perforation site B.

Cluster 4 consists of the two outlier findings FA_INFRA and FF_SUPRA. This group is characterized by significant:

- $\quad$ High occurrence of perforation site C.

\section{Discussion}

For perforations of the stomach and first portion of the duodenum, we found free air in $87 \%$ of cases above all intraperitoneal supramesocolic located (Figure 4), with a PPV equal to $44 \%$. 

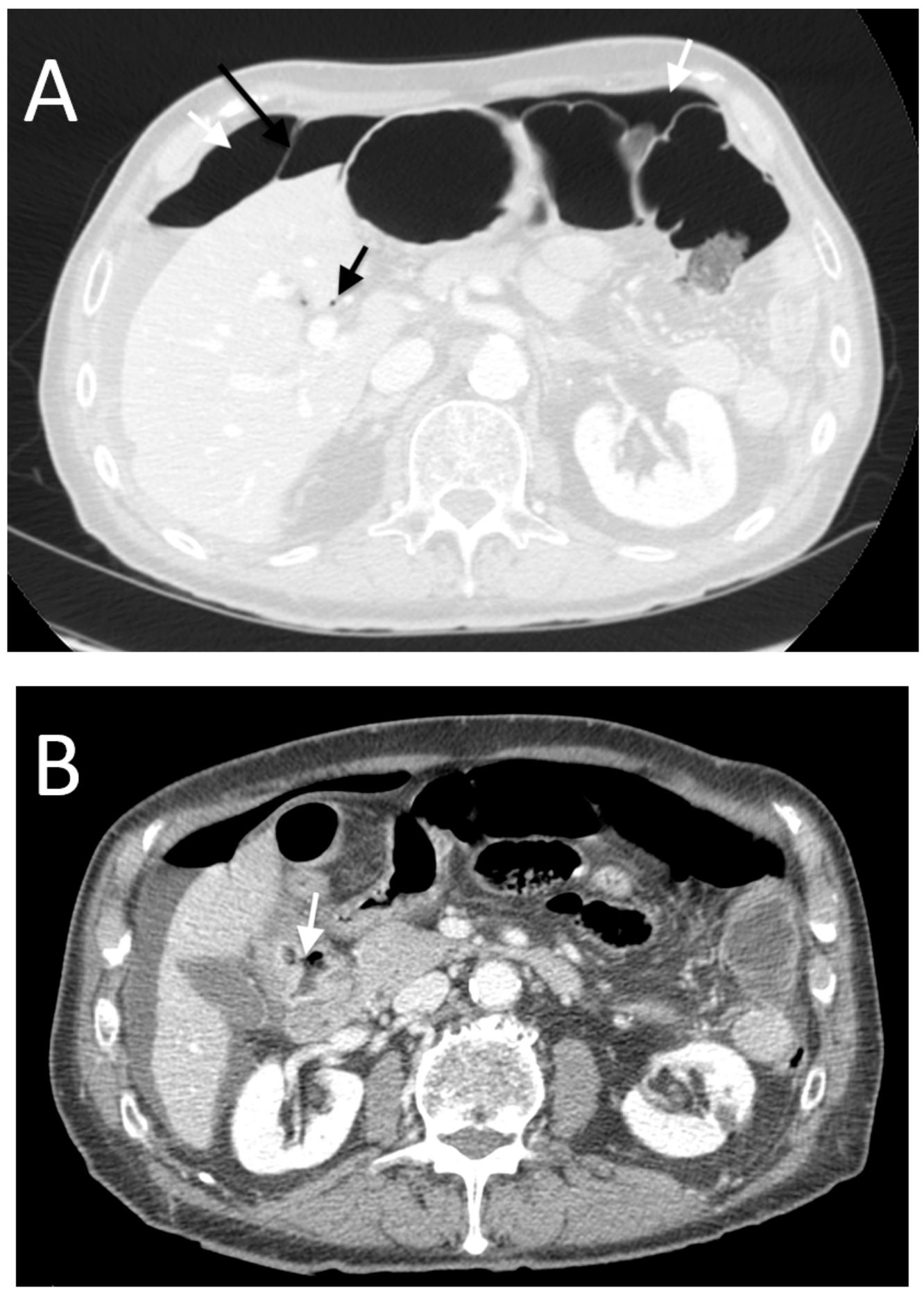

Figure 4. An 82-year-old male with perforation of the first portion of the duodenum caused by a peptic ulcer. The CT images show subdiaphragmatic free peritoneal air (white arrows in (A)) with "falciform ligament sign" (long black arrow in (A)). Note the periportal free air sign (short black arrow in (A)). In this case, we also found a focal wall defect (arrow in (B)).

These data are in agreement with data from the literature, in particular Yeung et al. in 2004 [9], Furukawa et al. in 2005 [12] and Cho et al. in 2009 [13], whose studies showed that in patients with perforation of the duodenal bulb or stomach, pneumoperitoneum is usually abundant, and it is noted around the liver and stomach, with frequent "falciform ligament sign" and "periportal free gas sign". In 19\% of gastroduodenal perforation cases, we found free retroperitoneal air (Figure 5) (PPV of 38\%). According to the literature, 
perforation of the posterior wall of the stomach or the first portion of the duodenum can also cause free air in the lesser sac and also a walled-off or confined perforation [14].
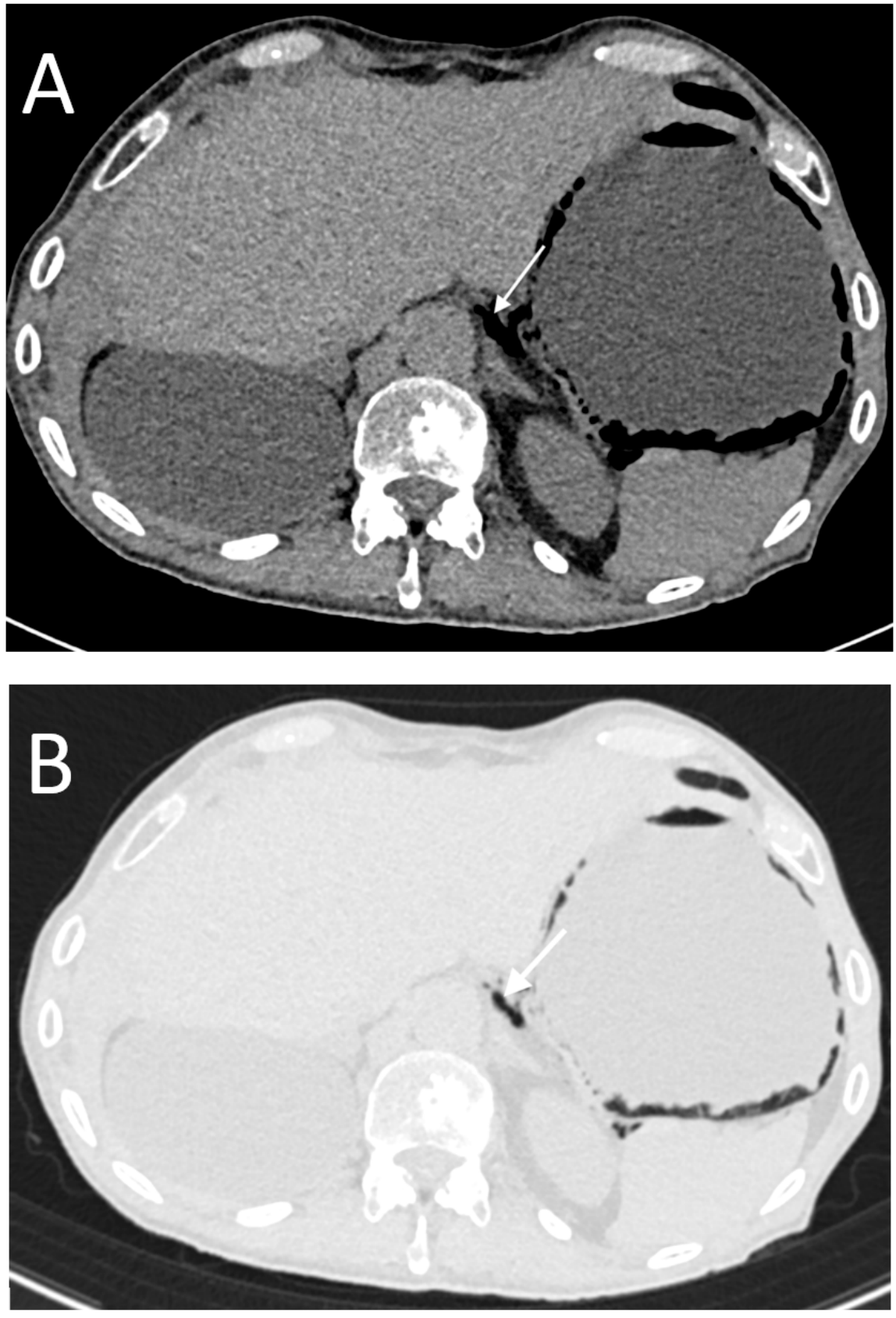

Figure 5. A 61-year-old male with perforation of the posterior wall of the stomach. The precontrast CT scan shows retroperitoneal free air (arrow in $(\mathbf{A}, \mathbf{B})$ ) only, with no evidence of gastric wall breach. Note the diffuse parietal pneumatosis of the gastric wall.

Moreover, extraluminal free air or gas bubbles located only in the retroperitoneal space, in particular in the right anterior pararenal space, has been reported as a reliable CT finding for diagnosing duodenal perforation beyond the bulbar segment, where gas typically outlines the lateral border of the psoas muscle [15]. Air bubbles close to the perforation site were found in $77 \%$ of patients in Group A, with a PPV equal to $41 \%$. Regarding the evidence of free abdominal fluid, in our study, $84 \%$ of gastroduodenal perforation (PPV of 38\%) was found, mainly intraperitoneal with evidence of retroperitoneal fluid in just $12 \%$ of cases (PPV of $23 \%$ ). Free fluid was both supra and inframesocolic located in 
$85 \%$ of cases with a PPV of $46 \%$, whereas only supramesocolic fluid was found in $8 \%$ of cases. This result differs somewhat from the study of Ghekiere in 2007 [16], reporting that supramesocolic free fluid between the head of the pancreas and duodenum had the highest PPV for gastroduodenal ulcer perforation. In gastroduodenal perforation, we found a higher PPV of segmental abnormal wall thickness (Figure 6) and segmental abnormal wall enhancement at the perforation site (PPVs of $38 \%$ and $46 \%$, respectively) than the other three groups. This is an interesting finding, because few authors in the literature evaluated the predictive value of these findings according to the different perforation sites.
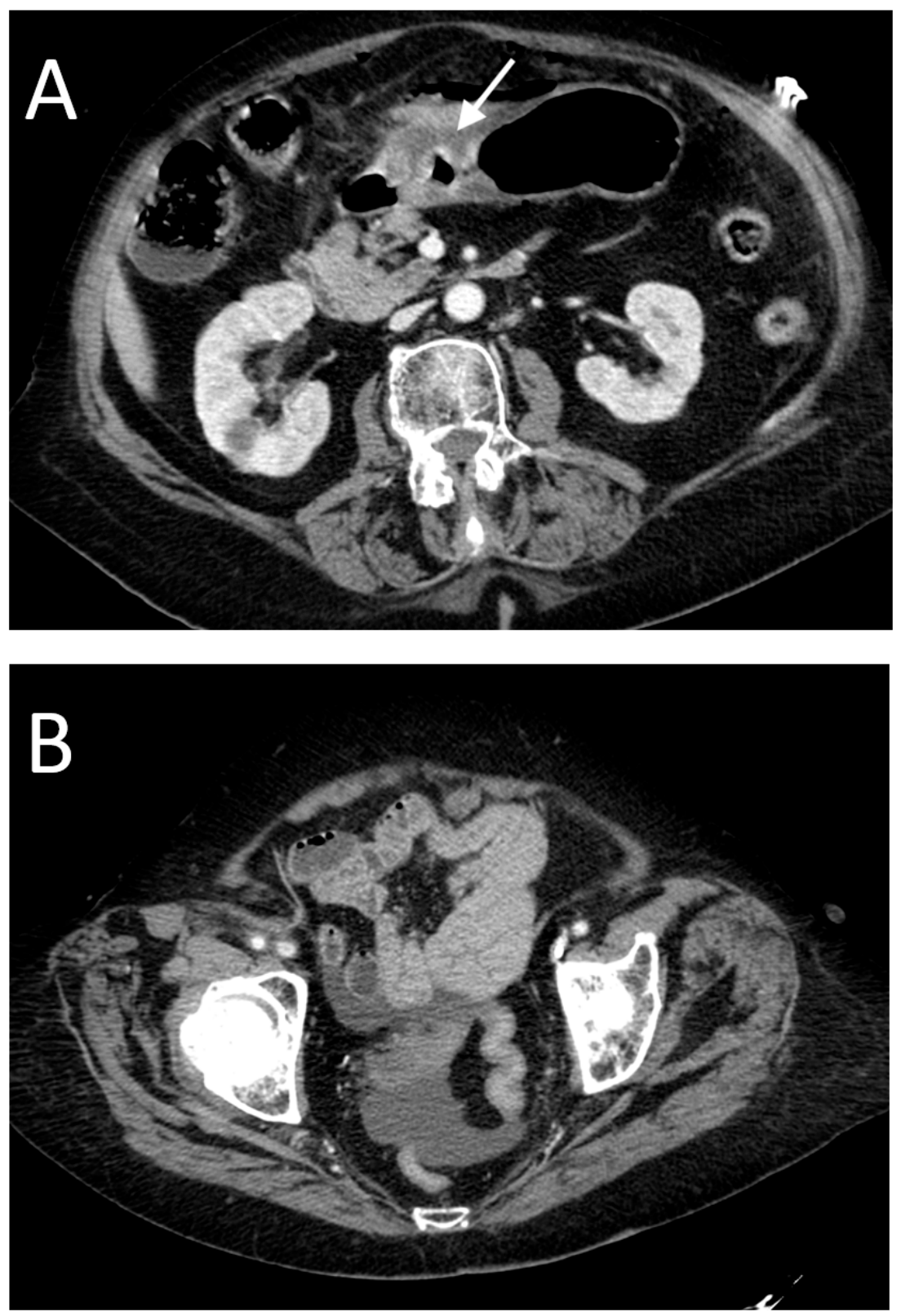

Figure 6. A 75-year-old female with perforation of the anterior gastric wall. In this case, CT shows focal abnormal wall thickening at the site of perforation (arrow in (A)), with the presence of a peripheral small amount of free air. There is also free fluid in the pelvis (B).

We found a focal wall defect (Figure 7 ) in $42 \%$ of patients with gastric or duodenal perforation but with a PPV of $38 \%$, which could be considered quite with high respect to that found in Groups B-D (PPVs of 24\%,12\% and 26\%, respectively). 

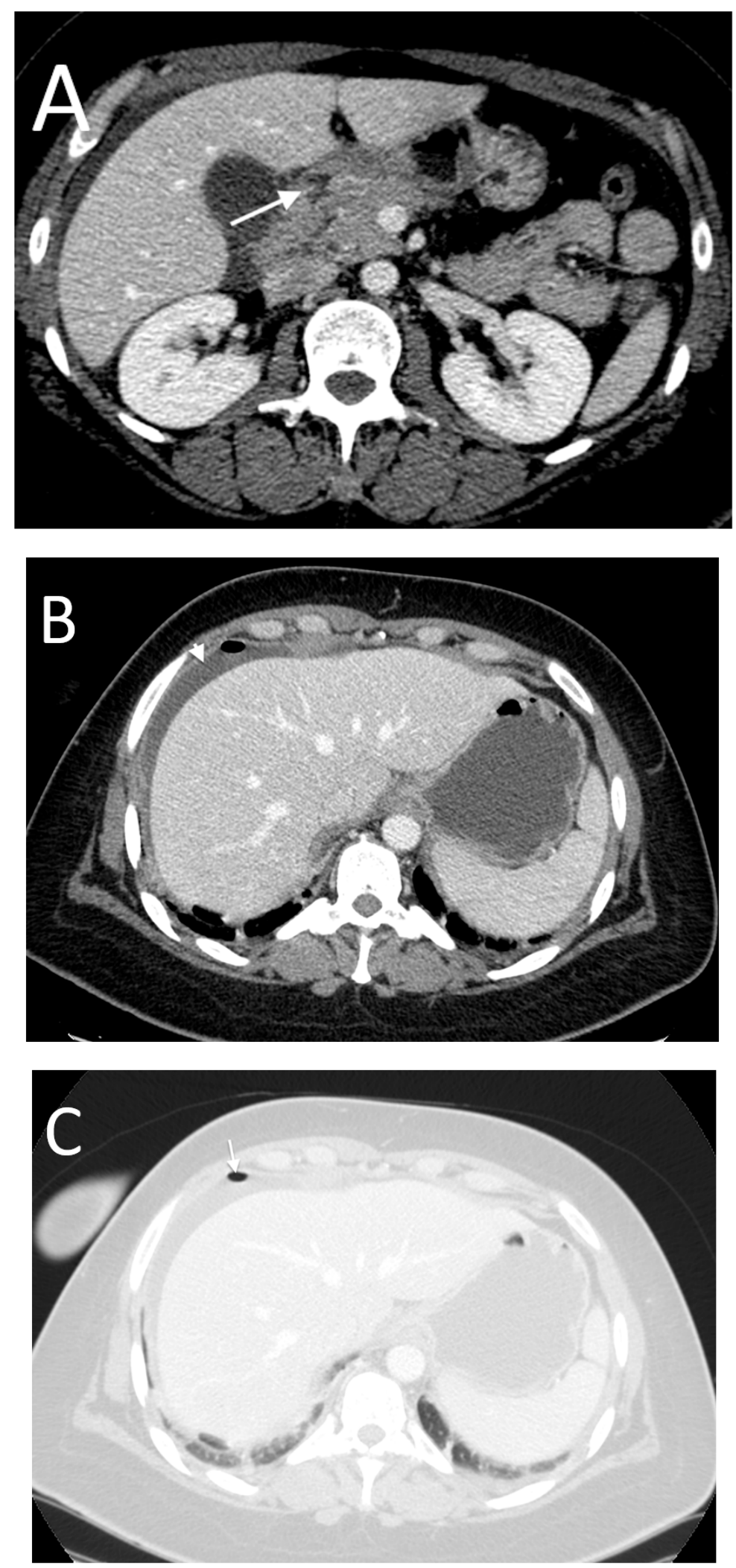

Figure 7. A 45-year-old female with perforation of the anterior gastric wall. In this case, we found a defect of continuity (arrow in (A)) at the site of perforation and subdiaphragmatic free fluid (arrowhead in $(\mathbf{B}))$ but a very small amount of free air (arrow in $(\mathbf{C})$ ).

Fat stranding was found in $58 \%$ of gastroduodenal perforations in our study, with the highest PPV (35\%) close to the perforation site. Lastly, we found distension of the 
upstream viscera in $61 \%$ of cases of perforation of the stomach and duodenum (PPV of $45 \%$ ), whereas in $58 \%$ of patients, we also found a collapse of the downstream loops (PPV of $39 \%$ ), suggestive of hypotonia of the hollow viscus before the perforation site and spasticity of the visceral tract down to the injured tract.

Regarding perforations of the small bowel loops, we found free air in $33 \%$ of cases, with a low PPV (10\%). This result is in agreement with the literature [11]. In this type of perforation, we found free air bubbles in $61 \%$ of cases (Figure 8 ), and this finding also appears to be in agreement with the literature [11]. However, in Group B of our patient population, we found that small air bubbles located in inframesocolic spaces achieve the highest PPV (50\%), and this is an interesting and relevant finding in CT diagnosis of the correct site of perforation.
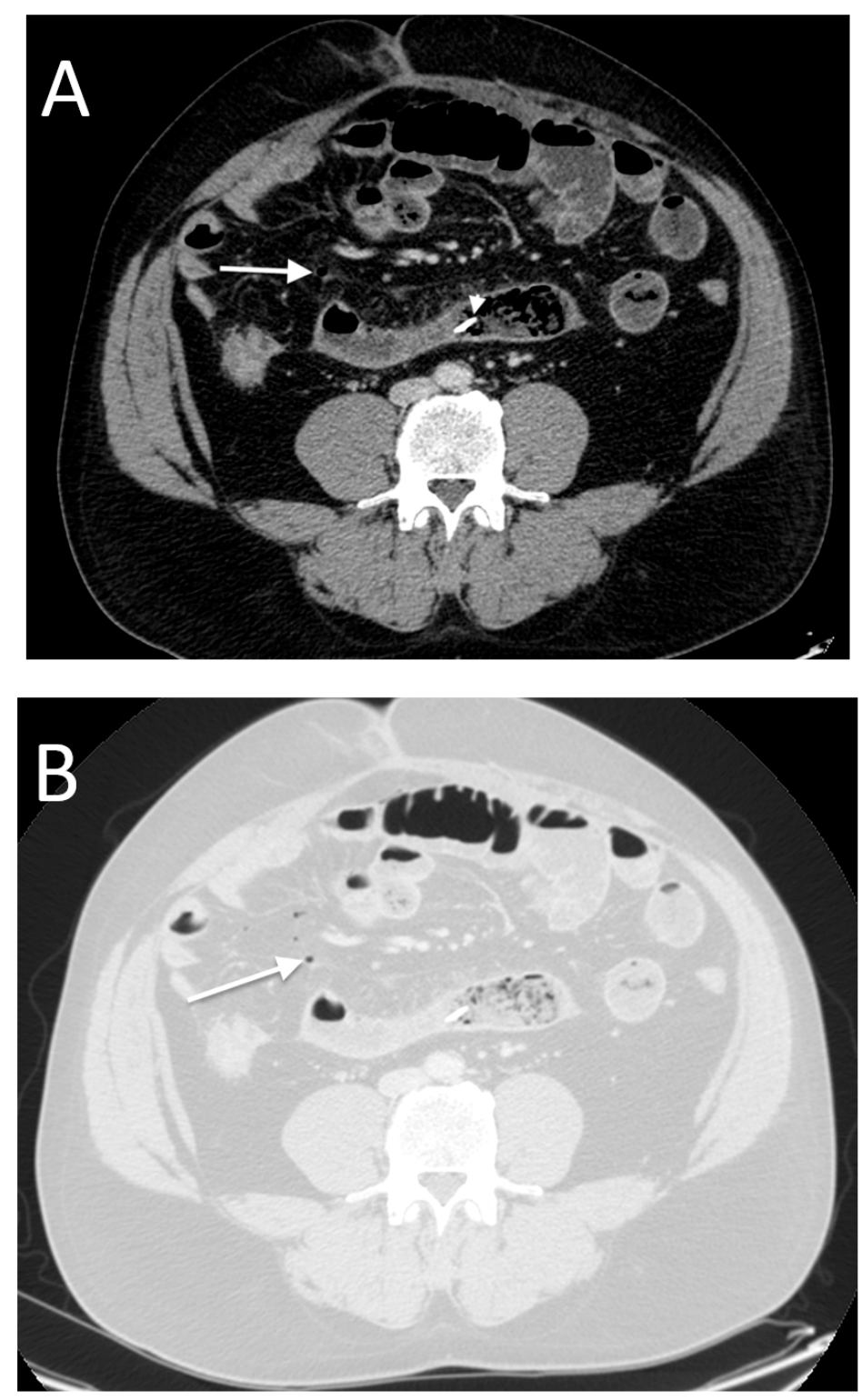

Figure 8. A 54-year-old male with ileal perforation. Only inframesocolic air bubbles (arrow in (A,B)) were found, with no free peritoneal fluid. Note the hyperdense foreign body in the small bowel loop (arrowhead in (A), a chicken bone).

Regarding the evidence of air bubbles close to the perforated loop, it is interesting to note that in our experience, they had a low PPV (PPV of 16\%), unlike the known literature (11). We found segmental abnormal wall thickness in patients of Group B and 
enhancement in $61 \%$ and $78 \%$ of cases (Figure 9 ), with a not-so-high PPV (16\% and $25 \%$, respectively) regarding the presumptive site of perforation. This finding could be due to the nonspecificity of the bowel wall thickening finding, which can also be found in association with other sites of perforation.
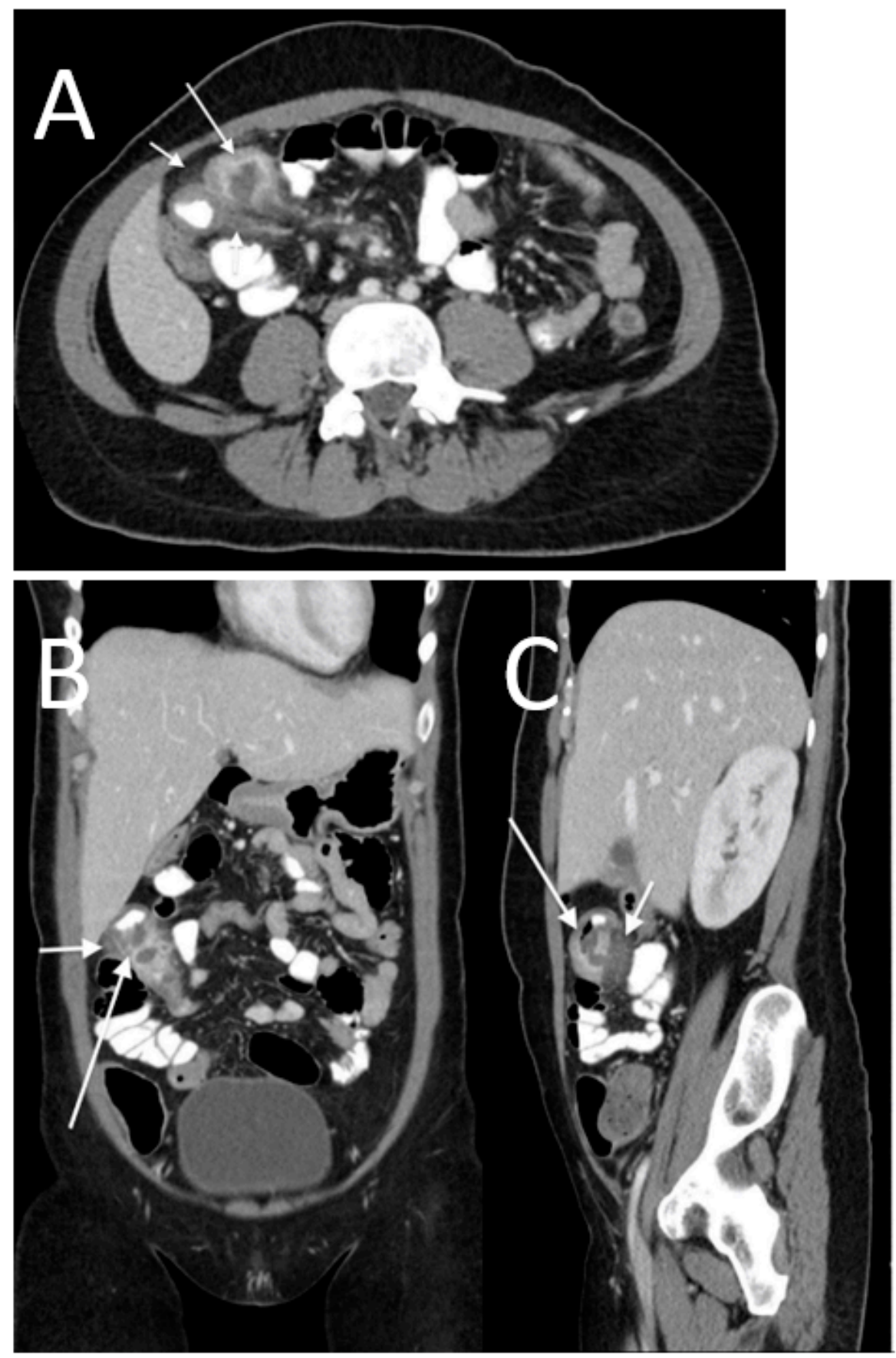

Figure 9. A 35-year-old female with aspergillosis of the ileum and surgical diagnosis of the ischemic ulcerative circumferential lesion at the proximal ileum involving all layers of the ileal wall with concealed perforation. The axial (A), coronal (B) and sagittal (C) images show focal posterior bowel wall disruption with increased enhancement and thickness of the involved bowel segment (long arrows). Surrounding fat stranding and a small amount of fluid are noted (short arrows).

In Group B (small bowel), the upstream loops to the site of perforations were distended in $39 \%$ (PPV of $17 \%$ ) of cases. Air bubbles and fat stranding were found close to the 
perforation site in $50 \%$ of patients but with low PPVs of $16 \%$ and $17 \%$. A relatively higher PPV for Group B was found in the wall thickening and enhancement of the downstream loops from the perforation site ( $22 \%$ and $23 \%$, respectively).

In colonic perforations from the cecum to the descending colon, free abdominal air was found in $63 \%$ of patients, always intraperitoneal, mostly supra- and inframesocolic (50\%) (Figure 10).
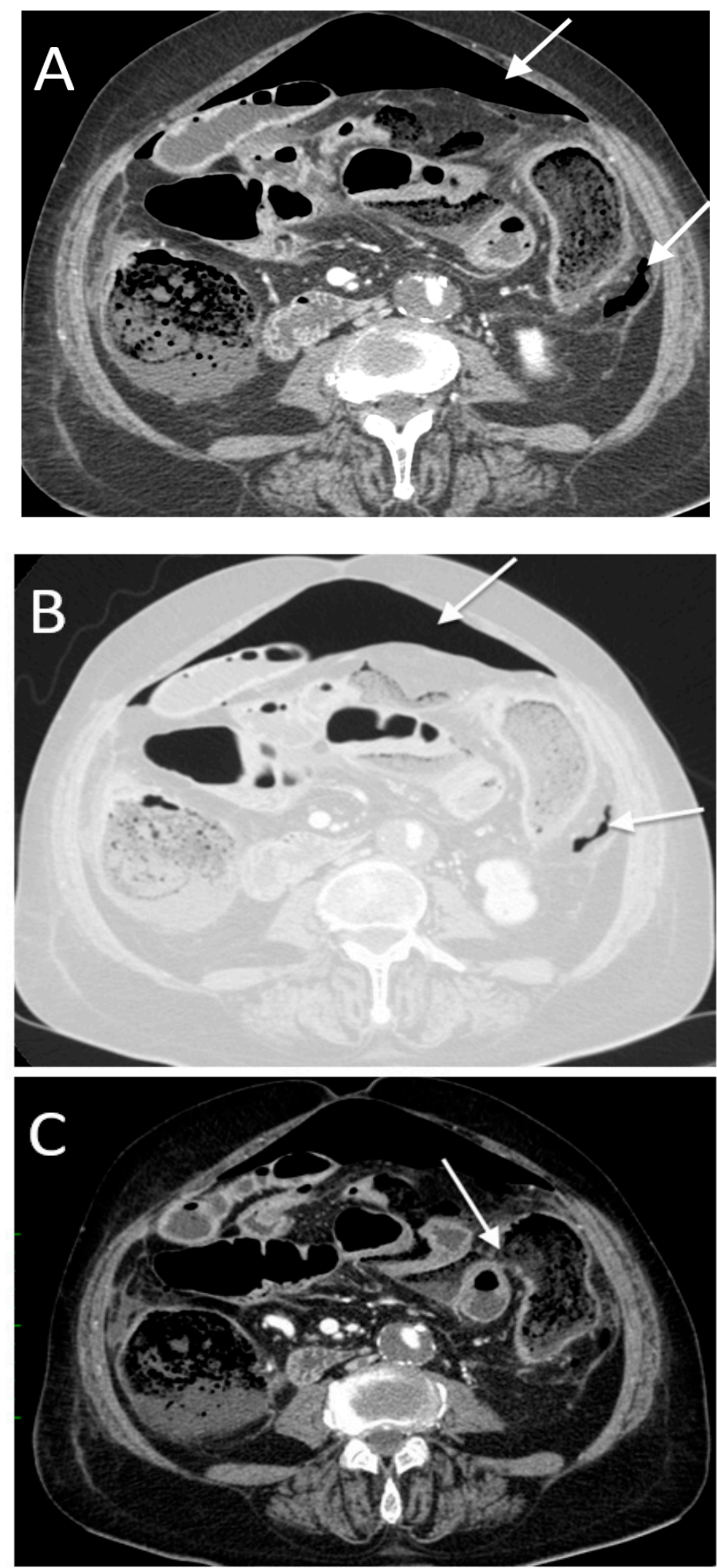

Figure 10. Cont. 


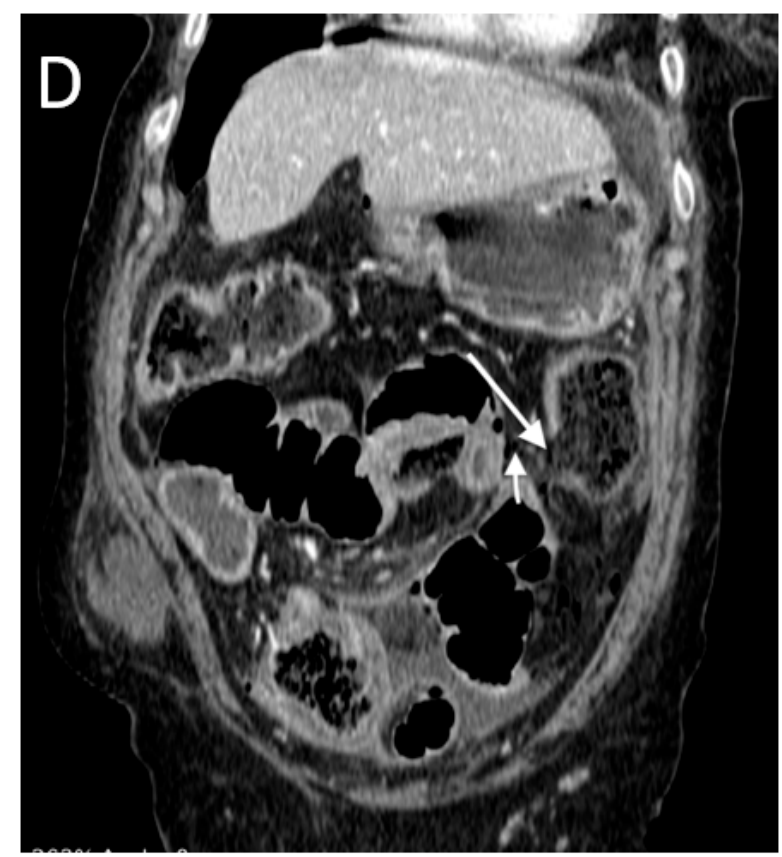

Figure 10. A 67-year-old female with a descending colon perforation. CT images show both supraand inframesocolic free intraperitoneal air (arrows in (A,B)). A focal wall defect was identified (arrow in $(\mathbf{C}, \mathbf{D})$ ). Note the air bubbles near the perforation site (short arrow in (D)) and the reactive segmental wall thickening with the submucosal edema of the ileal loop close to the colonic wall discontinuity.

We found only inframesocolic free air in $20 \%$ of cases but with a high PPV (67\%). These data are in agreement with those from literature, reporting that the presence of free air only in the inframesocolic space tends to be related to colonic perforation [14]. In our patients, upstream intestinal segments were distended in $50 \%$ of cases, and downstream loops collapsed in 50\%, but the PPVs were low (19\% and 17\%, respectively). Interestingly, the fat stranding close to the perforation site was present in $88 \%$ of cases (PPV of $27 \%$ ), and $25 \%$ of patients presented fluid collections (PPV of $18 \%$ ). The combination of free intraperitoneal air and free supramesocolic fluid had a high occurrence in Group C (Figure 2). For sigmoid and rectum perforation (Group D), we found free air mainly inside the peritoneum (83\%), especially supra- and inframesocolic (53\%), but this latter finding had a lower PPV of 33\% compared to the finding related to perforation of the stomach and duodenum (Group A, $38 \%$ ). In Group D, we did not find free air inframesocolic only, and this finding differs somewhat from that of the literature, reporting that if free gas is present only in the pelvis, usually the site of perforation is related to the colon or the sigmoid colon [14]. For sigmoid perforation, although it was found in $25 \%$ of cases, free retroperitoneal air had a high PPV (54\%). In fact, a sigmoid diverticulum can perforate into the mesosigmoid, with gas tracking into the retroperitoneum [14]. According to the literature, free retroperitoneal gas, often in the anterior pararenal space, may also be due to perforations during colonoscopy at the level of the posterior wall of the sigmoid of the ascending and descending colon [17].

A combination of intra- and retroperitoneal free air was found in our study in $22 \%$ of cases but with a high PPV of 57\%. The evidence of air randomly distributed in the peritoneal and retroperitoneal space could be a challenge in detecting the site of perforation, especially in the presence of extraluminal fecal material. In our experience, we found two cases of stercoral perforation (Figure 11), which is a distinct clinical and pathologic entity [18] caused in most cases by a fecaloma and characterized by the presence of both air and fecal material in the extraluminal space. 

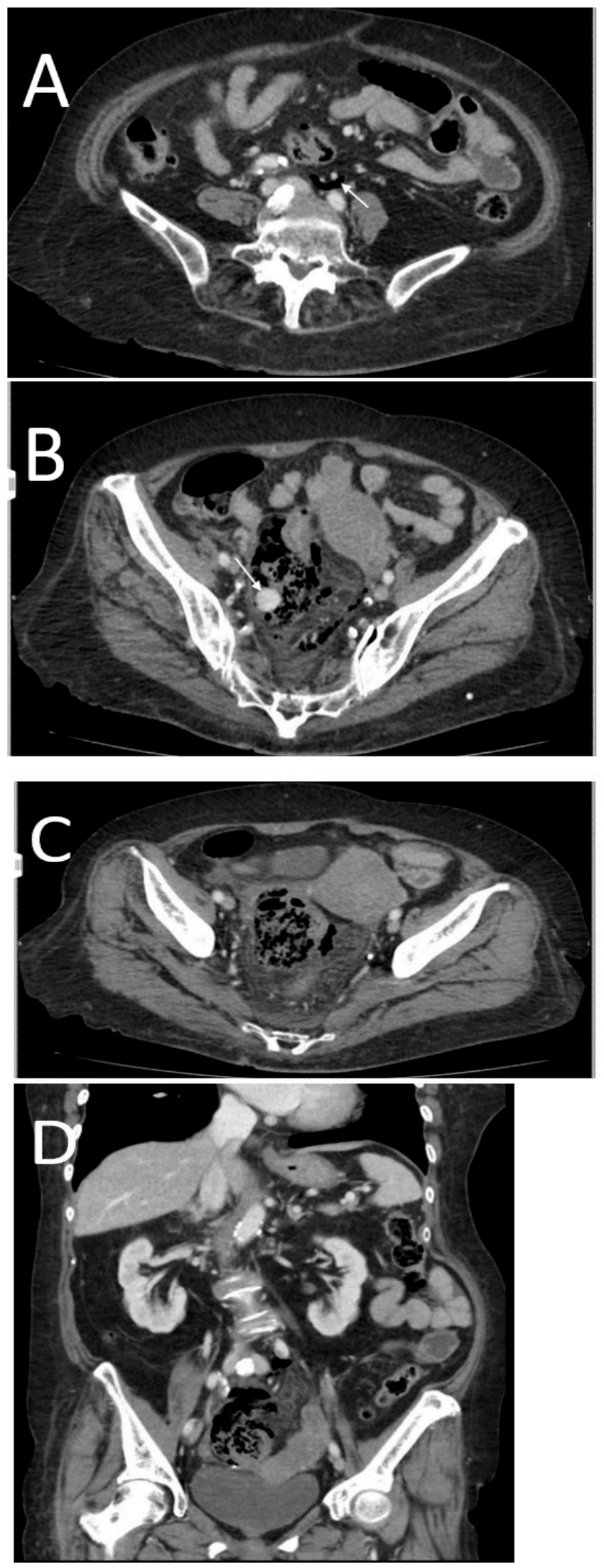

Figure 11. Cont. 


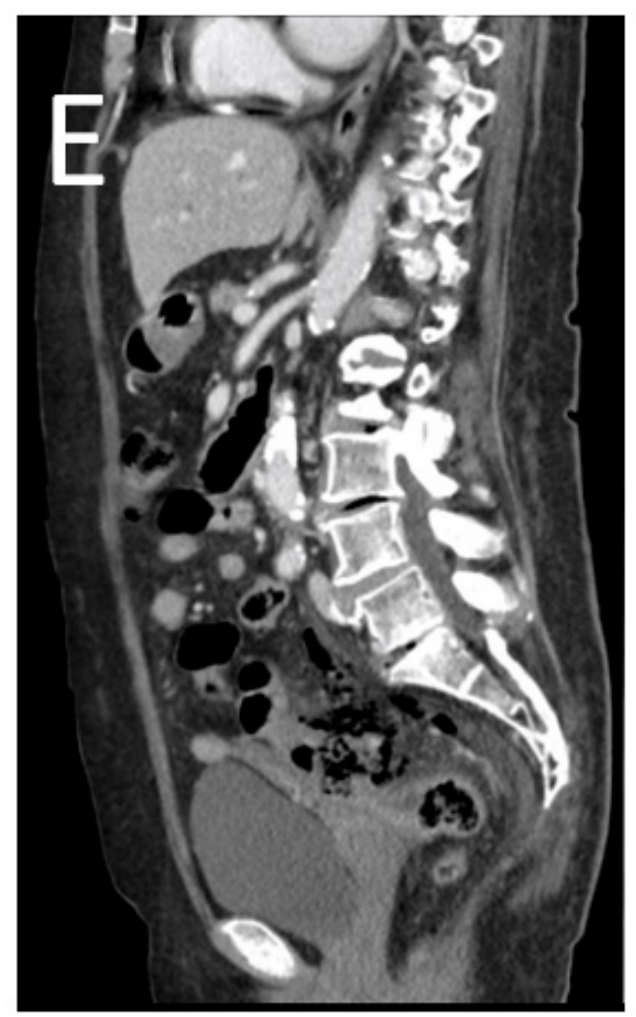

Figure 11. A 69-year-old female with a history of santol seed ingestion. Surgical diagnosis was full thickness of necrosis of the upper rectum with retained santol seed in the submucosal layer. CT shows retroperitoneal free air in the inframesocolic compartment (arrow in (A)), round hyperdense opacification in the middle of the fecal-like content adjacent to the involved upper rectum (arrow in (B)) and free air close to the involved upper rectum (C). Note the focal bowel wall disruption with abnormal thickness and enhancement of the involved upper rectum $(\mathbf{D}, \mathbf{E})$.

The highest PPV of 59\% was found in our study for perivisceral fluid collection in $46 \%$ of perforations of the sigmoid colon and rectum, followed by intra- and retroperitoneal free air bubbles (30\% of cases, PPV of $58 \%$ ). Additionally, retroperitoneal free fluid had a relatively high PPV of 54\% for sigmoid rectal perforations in our study. An interesting finding never investigated before in the literature as per our knowledge is the "perivisceral fat stranding" finding, which, in our case, had the highest PPV of 37\% for sigmoid colorectal perforations than other sites and could be helpful to emergency radiologists in diagnosis. For this group of intestinal perforations, in $46 \%$ of cases, the fat stranding sign was located at the nearest upstream intestinal segment more than in the exact site of perforation (Figure 12), showing a PPV of $100 \%$ (Table 1). Regarding the feature of the upstream and downstream loops in Group D, we did not find any relevant information on luminal distension, but a segmental abnormal wall thickness in the upstream loops (descending colon and proximal sigmoid colon) was noted in $54 \%$ of cases.

In the evaluation and reporting of the MDCT examination of patients with suspected gastrointestinal perforations, it is strongly important to be able to detect the cause and site of perforation, being either the type of surgical approach (laparotomy vs. laparoscopy) or a conservative therapy closely depending on this information [1]. 

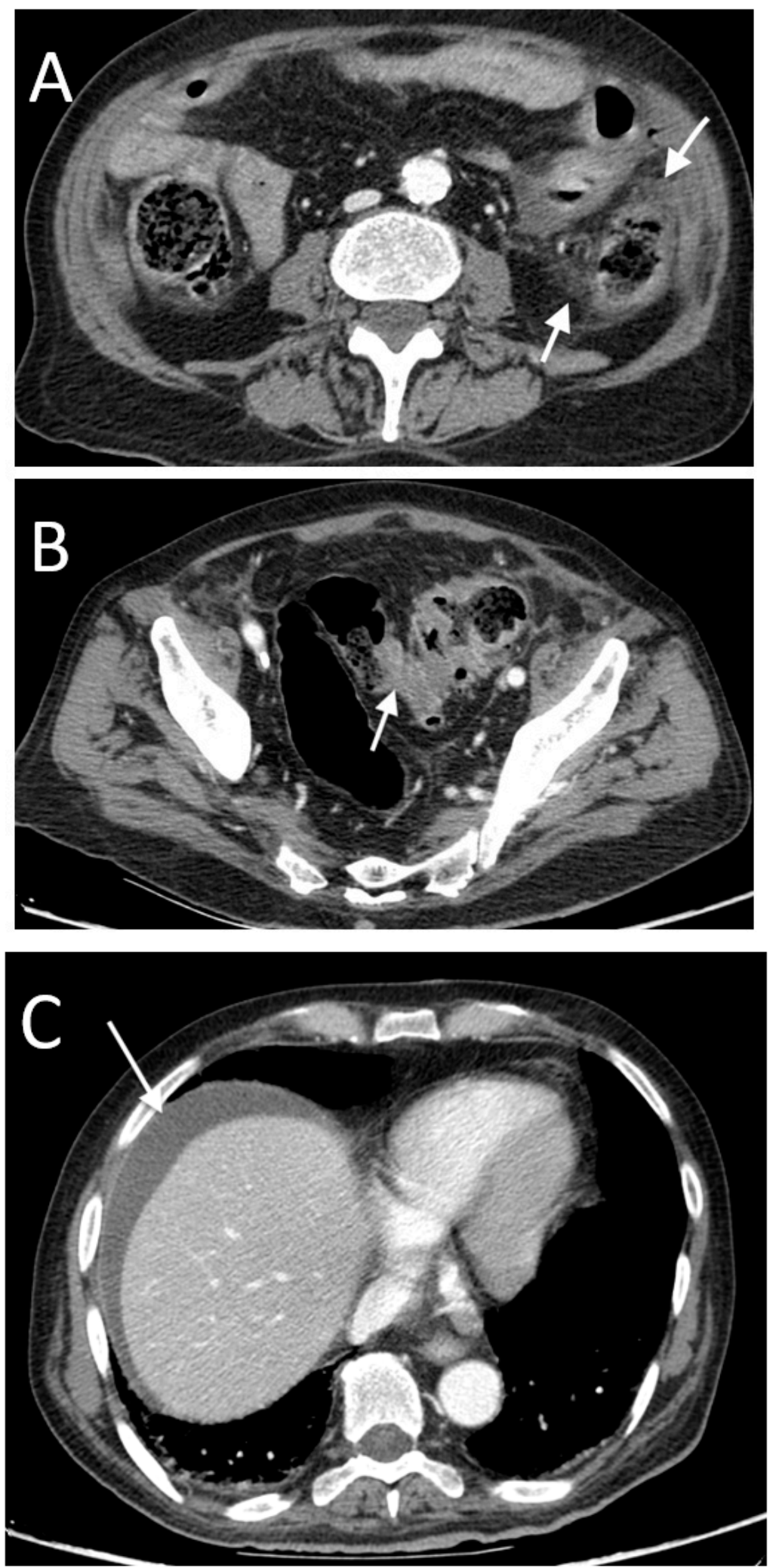

Figure 12. A 77-year-old male with sigmoid colon perforation. Note perivisceral fat stranding and edema surrounding the descending colon (arrows in (A)). The perforated segment showed wall edematous thickening and enhancement (arrow in (B)). There was no free peritoneal air evidence but perihepatic free fluid (arrow in (C)). 
In patients with gastroduodenal ulcer perforation, laparoscopy is a very suitable approach for perforations of the anterior or lateral surface, with better clinical outcomes $[5,19]$. Instead, perforations of the posterior face of the stomach or duodenum could be better managed by regular open surgery [1]. In the surgical literature, small bowel perforations are best treated by laparotomy, and, among colonic perforations, those caused by cancer would be preferably repaired by open surgery [1]. In contrast, management of perforations from sigmoid acute diverticulitis depends on the stage of the disease, as well as the clinical stability of the patient and the experience of the surgical team [1]. In stable patients with radiological evidence of extraluminal air, MDCT findings, including distant versus pericolonic air, extravasation of rectal contrast medium and the presence of an associated abscess, have been reported to be able to predict failure of initial nonoperative management [20]. Colonic diverticula perforation is one of the most common acute abdominal conditions that lead to patients being submitted to emergency CT examination. According to the modified Hinchey classification (Kaiser et al. 2005) [20], acute diverticulitis may be categorized into six stages ( 0 , Ia, Ib, II, III, IV). Most patients with uncomplicated diverticulitis (0-clinical or Ia - pericolic inflammation or phlegmon) are treated conservatively. Patients with an abscess at a pericolonic site (Ib) or in the pelvis or retroperitoneal space (II) are usually treated conservatively or with percutaneous drainage [20]. Conversely, when there is clinical and/or radiological suspicion of generalized purulent (III) or fecal (IV) peritonitis, emergent surgical intervention should be considered, usually in the form of either sigmoid resection and primary anastomosis (with or without proximal diversion) or Hartmann's procedure [21,22]. Moreover, in the acute emergent setting, bowel distention, as displayed by preoperative CT imaging, may limit the use of laparoscopy due to a small operative space and an increased risk of iatrogenic injuries [23]. Finally, regarding the cecal appendix perforations, preoperative findings of a localized appendiceal perforation with peritonitis could be a reason for switching from an appendectomy by laparoscopy to an open procedure [24].

\section{Conclusions}

Overall, our results appear interesting regarding the MDCT findings according to the site of perforation, adding some more new information to what is already known and has been reported in the radiologic literature. In particular, we did not find only inframesocolic free air in the perforation of the sigmoid colorectal but both supra- and inframesocolic or supramesocolic only. We rarely observed only supramesocolic free fluid in gastroduodenal perforations, and we found low PPVs for air bubbles close to the perforated loop in small bowel perforation $(16 \%)$ and from the caecum to the descending colon (14\%). A high PPV of segmental abnormal wall thickness and enhancement at the exact site of perforation was found in our experience, especially in gastroduodenal perforations (PPVs of $38 \%$ and $46 \%$, respectively), whereas a high PPV of fat stranding (37\%) was noted in the case of sigmoid colon and rectum perforations next to the upstream segment in $46 \%$ of cases with a PPV of $100 \%$. Finally, we found distension of the upstream viscera and collapse of the downstream intestinal segment with respect to the site of perforation in a relevant percentage of patients (especially in perforations of the stomach, duodenum and from the caecum to the descending colon).

Although ours represents a preliminary study on a limited number of patients, these initial data appear interesting to provide new additional information in cases of doubtful MDCT findings that could be used by radiologists in the identification of the gastrointestinal perforation site in order to be able to support surgeons in choosing the most appropriate treatment modality.

Author Contributions: Conceptualization, S.R. and C.S.; methodology, S.R.; software, C.S. and D.P.; validation, S.R. and A.S.; formal analysis, D.P.; investigation, S.R., C.S., M.P., F.E., A.S., W.J. and K.K.; resources, S.R., C.M. and F.P.; data curation, C.S., C.M. and D.P.; writing-original draft preparation, C.S. and S.R.; writing—review and editing, S.R., C.S., A.S. and D.P.; visualization; supervision, S.R. and F.P. All authors have read and agreed to the published version of the manuscript. 
Funding: This research received no external funding.

Institutional Review Board Statement: The study was conducted according to the guidelines of the Declaration of Helsinki. Institutional ethical review and approval were waived for this study, due to the retrospective nature of the investigation not based on new or not approved techniques and methods.

Informed Consent Statement: No informed consent was asked because of the retrospective form of the study not based on sensible data published.

Data Availability Statement: Not applicable.

Conflicts of Interest: The authors declare no conflict of interest.

\section{References}

1. Taourel, P.; Baert, A.L.; Reiser, M.F.; Hricak, H.; Knauth, M. Medical Radiology Diagnostic Imaging, CT of the Acute Abdomen, Bowel Perforations; Springer: Berlin/Heidelberg, Germany, 2011; pp. 309-327.

2. Hines, J.; Rosenblat, J.; Duncan, D.R.; Friedman, B.; Katz, D.S. Perforation of the mesenteric small bowel: Etiologies and CT findings. Emerg. Radiol. 2012, 20, 155-161. [CrossRef]

3. Kothari, K.; Friedman, B.; Grimaldi, G.M.; Hines, J.J. Nontraumatic large bowel perforation: Spectrum of etiologies and CT findings. Abdom. Radiol. 2017, 6, 177-2608. [CrossRef] [PubMed]

4. Zissin, R.; Osadchy, A.; Gayer, G. Abdominal CT findings in small bowel perforation. Br. J. Radiol. 2009, 82, 162-171. [CrossRef]

5. Simonetti, I.; Puglia, M.; Tarotto, L.; Palumbo, F.; Esposito, F.; Sciuto, A.; Ragozzino, A. When traditions become dangerous: Intestinal perforation from unusual foreign body-Case report and short literature review. Eur. J. Radiol. Open 2019, 6, 152-155. [CrossRef] [PubMed]

6. Siu, W.T.; Leong, H.T.; Law, B.K.B.; Chau, C.H.; Li, A.C.N.; Fung, K.H.; Tai, Y.P.; Li, M.K.W. Laparoscopic Repair for Perforated Peptic Ulcer: A randomized controlled trial. Ann. Surg. 2002, 235, 313-319. [CrossRef] [PubMed]

7. Re, G.L.; La Mantia, F.; Picone, D.; Salerno, S.; Vernuccio, F.; Midiri, M. Small Bowel Perforations: What the Radiologist Needs to Know. Semin. Ultrasound CT MRI 2016, 37, 23-30. [CrossRef]

8. Grassi, R.; Romano, S.; Pinto, A.; Romano, L. Gastro-duodenal perforations: Conventional plain film, US and CT findings in 166 consecutive patients. Eur. J. Radiol. 2004, 50, 30-36. [CrossRef] [PubMed]

9. Yeung, K.-W.; Chang, M.-S.; Hsiao, C.-P.; Huang, J.-F. CT evaluation of gastrointestinal tract perforation. Clin. Imaging 2004, 28, 329-333. [CrossRef]

10. Hainaux, B.; Agneessens, E.; Bertinotti, R.; De Maertelaer, V.; Rubesova, E.; Capelluto, E.; Moschopoulos, C. Accuracy of MDCT in Predicting Site of Gastrointestinal Tract Perforation. Am. J. Roentgenol. 2006, 187, 1179-1183. [CrossRef]

11. Kim, S.H.; Shin, S.S.; Jeong, Y.Y.; Heo, S.H.; Kim, J.W.; Kang, H.K. Gastrointestinal Tract Perforation: MDCT Findings according to the Perforation Sites. Korean J. Radiol. 2009, 10, 63-70. [CrossRef]

12. Furukawa, A.; Sakoda, M.; Yamasaki, M.; Kono, N.; Tanaka, T.; Nitta, N.; Kanasaki, S.; Imoto, K.; Takahashi, M.; Murata, K.; et al. Gastrointestinal tract perforation: CT diagnosis of presence, site, and cause. Gastrointest. Radiol. 2005, 30, 524-534. [CrossRef] [PubMed]

13. Cho, H.S.; Yoon, S.E.; Park, S.H.; Kim, H.; Lee, Y.-H.; Yoon, K.-H. Distinction between upper and lower gastrointestinal perforation: Usefulness of the periportal free air sign on computed tomography. Eur. J. Radiol. 2009, 69, 108-113. [CrossRef] [PubMed]

14. Singh, J.P.; Steward, M.J.; Booth, T.C.; Mukhtar, H.; Murray, D. Evolution of imaging for abdominal perforation. Ann. R. Coll. Surg. Engl. 2010, 92, 182-188. [CrossRef]

15. Kunin, J.R.; Korobkin, M.; Ellis, J.H.; Francis, I.R.; Kane, N.M.; Siegel, S.E. Duodenal injuries caused by blunt abdominal trauma: Value of CT in differentiating perforation from hematoma. Am. J. Roentgenol. 1993, 160, 1221-1223. [CrossRef] [PubMed]

16. Ghekiere, O.; Lesnik, A.; Hoa, D.; Laffargue, G.; Uriot, C.; Taourel, P. Value of Computed Tomography in the Diagnosis of the Cause of Nontraumatic Gastrointestinal Tract Perforation. J. Comput. Assist. Tomogr. 2007, 31, 169-176. [CrossRef] [PubMed]

17. Burling, D.; Halligan, S.; Slater, A.; Noakes, M.J.; Taylor, S.A. Potentially Serious Adverse Events at CT Colonography in Symptomatic Patients: National Survey of the United Kingdom. Radiology 2006, 239, 464-471. [CrossRef] [PubMed]

18. Rozenblit, A.; Cohen-Schwartz, D.; Wolf, E.; Foxx, M.; Brenner, S. Stercoral Perforation of the Sigmoid Colon: Computed Tomography Findings. Clin. Radiol. 2000, 55, 727-729. [CrossRef] [PubMed]

19. Cirocchi, R.; Søreide, K.; Di Saverio, S.; Rossi, E.; Arezzo, A.; Zago, M.; Abraha, I.; Vettoretto, N.; Chiarugi, M. Meta-analysis of perioperative outcomes of acute laparoscopic versus open repair of perforated gastroduodenal ulcers. J. Trauma Acute Care Surg. 2018, 85, 417-425. [CrossRef] [PubMed]

20. Kaiser, A.M.; Jiang, J.-K.; Lake, J.P.; Ault, G.; Artinyan, A.; Gonzalez-Ruiz, C.; Essani, R.; Beart, R.W. The Management of Complicated Diverticulitis and the Role of Computed Tomography. Am. J. Gastroenterol. 2005, 100, 910-917. [CrossRef] [PubMed]

21. Francis, N.K.; Sylla, P.; Abou-Khalil, M.; Arolfo, S.; Berler, D.; Curtis, N.J.; Dolejs, S.C.; Garfinkle, R.; Gorter-Stam, M.; Hashimoto, D.A.; et al. EAES and SAGES 2018 consensus conference on acute diverticulitis management: Evidence-based recommendations for clinical practice. Surg. Endosc. 2019, 33, 2726-2741. [CrossRef] [PubMed] 
22. Tochigi, T.; Kosugi, C.; Shuto, K.; Mori, M.; Hirano, A.; Koda, K. Management of complicated diverticulitis of the colon. Ann. Gastroenterol. Surg. 2018, 2, 22-27. [CrossRef]

23. Mahmoud, N.N.; Riddle, E.W. Minimally Invasive Surgery for Complicated Diverticulitis. J. Gastrointest. Surg. 2017, 21, 731-738. [CrossRef] [PubMed]

24. Liu, S.-I.; Siewert, B.; Raptopoulos, V.; Hodin, R.A. Factors associated with conversion to laparotomy in patients undergoing laparoscopic appendectomy. J. Am. Coll. Surg. 2002, 194, 298-305. [CrossRef] 